\title{
Gas leakage from the biopsy valve: Does it matter in the era of COVID-19?
}

\section{(ㄷ)(1) $\odot$}

\author{
Author \\ Jean-Marc Dumonceau \\ Institution \\ Department of Gastroenterology, Charleroi University \\ Hospitals, Charleroi, Belgium \\ Bibliography \\ Endoscopy International Open 2021; 09: E450-E452 \\ DOI 10.1055/a-1339-1259 \\ ISSN 2364-3722 \\ (c) 2021. The Author(s). \\ This is an open access article published by Thieme under the terms of the Creative \\ Commons Attribution-NonDerivative-NonCommercial License, permitting copying \\ and reproduction so long as the original work is given appropriate credit. Contents
}

\author{
may not be used for commecial purposes, or adapted, remixed, transformed or \\ built upon. (https://creativecommons.org/licenses/by-nc-nd/4.0/) \\ Georg Thieme Verlag KG, Rüdigerstraße 14, \\ 70469 Stuttgart, Germany \\ Corresponding author \\ Jean-Marc Dumonceau, MD PhD, Service de \\ Gastroentérologie, Hôpital Civil Marie Curie, Chaussée de \\ Bruxelles 140, B 6042 Charleroi, Belgium \\ Fax: +32-71-922367 \\ jmdumonceau@hotmail.com
}

Coronavirus disease 2019 (COVID-19), which is caused by severe acute respiratory syndrome coronavirus 2 (SARS-CoV-2), has become a worldwide pandemic. It may transform itself in a succession of outbreaks and quiescent periods, requiring prolonged vigilance, as happened with the 1918 influenza pandemic, the most severe pandemic in history, which occurred in three waves. Nevertheless, return to routine endoscopy cannot be much deferred, as delayed diagnosis of some diseases increases mortality [1].

SARS-CoV-2 replicates in the tissues of the upper respiratory tract, including the pharynx, with a peak concentration before Day 5 , suggesting that patients are contagious at a time when symptoms are still mild. Respiratory transmission of SARS-CoV2 is dominant over transmission by direct or indirect (fomite) contact [2] and aerosols are thought to play a key role in it. Aerosols are particles that are produced when air flows across the surface of a liquid film; they are suspended in the air and can contain viruses such as SARS-CoV-2 [3]. They are usually classified according to their size as small ( $\leq 5-$ to $20-\mu \mathrm{m})$ droplets that travel long distances and large (20- to $100-\mu \mathrm{m})$ droplets that travel $<1 \mathrm{~m}$ and may splash into the eyes or mouth or settle on surfaces [4]. The possible generation of aerosols during upper gastrointestinal endoscopy remains debated, with only half the sources classifying upper gastrointestinal endoscopy as aerosol-generating, similar to coughing and much lower than $95 \%$ of sources for bronchoscopy [5]. Another transmission mechanism, if confirmed, could also be relevant: SARSCoV-2 RNA has been detected in tissue samples from the stomach, duodenum, and rectum of COVID-19 patients [6] and viable SARS-CoV-2 has been isolated from stool [7, 8]. In a meta- analysis, half the stool samples from patients with COVID-19 tested positive for virus RNA; worryingly, two-thirds of these patients had virus RNA detected even after respiratory specimens tested negative [9].

Data on the risk of SARS-CoV-2 transmission to health care workers in gastrointestinal endoscopy are contradictory. In two studies from Italy and the U.K. that included a total of 60 endoscopy centers, fewer than $4 \%$ of health care workers tested positive for SARS-CoV-2. Of note, almost $90 \%$ of infections occurred before the introduction of safety measures, such as use of personal protective equipment (PPE) and case selection/reduction in gastrointestinal endoscopy $[10,11]$. In contrast, a worldwide survey found that one-third of 163 endoscopy centers reported positive cases of SARS-CoV-2 infection among their healthcare workers despite the large use of PPE [12].

In this context, the research on previously unreported potential pathways of contamination during gastrointestinal endoscopy presented in the current issue of Endoscopy International Open may be critical [13]. The experiment design was simple: Urakawa et al. inserted, ex vivo, a colonoscope in a porcine rectal segment, then inflated the bowel, submerged the colonoscope in a water bath, and finally they passed various instruments through the biopsy valve in the working channel of the endoscope. During these maneuvers, gas frequently leaked at the level of the biopsy valve at low pressures and at the level of the handle of various endoscopy instruments, including snares, clips, and knifes, at higher pressures.

Future work should investigate several points: 
- The volume of the gas leak. The dead space in the working channel of the endoscope used by the authors is approximately $9 \mathrm{~cm}^{3}$. These $9 \mathrm{~cm}^{3}$ are filled with air from the room and are the first ones to escape through the biopsy valve. These are likely irrelevant in terms of contamination.

- Intraluminal pressures measured during standard endoscopy only should be used. In the current study, inflation pressures up to $75 \mathrm{~mm} \mathrm{Hg}$ were used in some of the experiments. Although an "average of maximum intraluminal pressure" $>100 \mathrm{~mm} \mathrm{Hg}$ was reported in a study cited by Urakawa et al., this pressure corresponded to contractions of the circumferential circular muscles of the colon haustrations on a sensor (no endoscopy was performed in that study) [14]. Pressures of 8 to $16 \mathrm{~mm} \mathrm{Hg}$ are more commonly used for endoscopy [15].

- Finally, the significance of these gas leaks, as assessed by the presence of aerosols or the detection of viral RNA in it, should be investigated. Various instruments such as particle sizers may be used to detect particles in aerosols and measure some of their characteristics, such as their number, concentration, and size distribution during endoscopic procedures. Knowing if aerosols are generated when introducing an endoscopy instrument through the biopsy valve is important because all of the precautions described to reduce the dispersion of aerosols during upper gastrointestinal endoscopy consist of interposing a barrier between the patient and the environment but none has taken the endoscope into account. Proposed barriers consist of fabric or masks with a hole applied to the patient's face [16, 17], a transparent plastic bag or plexiglass box placed around the patient's face $[18,19]$, or a sheet covering the whole patient and stretcher down to the ground [20].

If the authors' findings are confirmed to be significant in terms of contamination, they have the potential to impact the design of endoscopy accessories. Currently, to mitigate the risks, one could: (1) choose biopsy valves and endoscopy instruments that tend to leak less; (2) insert/remove endoscopy instruments quickly, at a low inflation pressure, without changing the insertion angle of the device; and (3) place a barrier with a hole on the biopsy valve when inserting an endoscopy instrument.

For the time being, triage of patients for urgent procedures, pre-endoscopy patient screening based on symptoms and/or testing for the presence of SARS-CoV-2 (point-of-care tests), segregation of clean and contaminated zones in endoscopy suites, physical distancing, rigorous sanitization procedures, and use of PPE remain the cornerstones for prevention of contamination.
Competing interests

The authors declare that they have no conflict of interest.

\section{References}

[1] Maringe C, Spicer J, Morris M et al. The impact of the COVID-19 pandemic on cancer deaths due to delays in diagnosis in England, UK: a national, population-based, modelling study. Lancet Oncol 2020; 21: 1023-1034

[2] Meyerowitz EA, Richterman A, Gandhi RT et al. Transmission of SARSCoV-2: a review of viral, host, and environmental factors. Ann Intern Med 2021; 174: 69-79 [Epub ahead of print 17 September 2020] doi: $10.7326 / \mathrm{M} 20-5008$

[3] Liu Y, Ning Z, Chen Y et al. Aerodynamic analysis of SARS-CoV-2 in two Wuhan hospitals. Nature 2020; 582: 557-560

[4] Judson SD, Munster VJ. Nosocomial transmission of emerging viruses via aerosol-generating medical procedures. Viruses 2019; 11: 940

[5] Jackson T, Deibert D, Wyatt G et al. Classification of aerosol-generating procedures: a rapid systematic review. BMJ Open Respir Res 2020; 7: e000730

[6] Xiao F, Tang M, Zheng X et al. Evidence for gastrointestinal infection of SARS-COV-2. Gastroenterology 2020; 158: 1831-1833.e3

[7] Jeong HW, Kim S-M, Kim H-S et al. Viable SARS-CoV-2 in various specimens from COVID-19 patients. Clin Microbiol Infect 2020; 26: $1520-1524$

[8] van Doorn AS, Meijer B, Frampton CMA et al. Systematic review with meta-analysis: SARS-CoV-2 stool testing and the potential for faecaloral transmission. Aliment Pharmacol Ther 2020; 52: 1276-1288

[9] Cheung KS, Hung IFN, Chan PPY et al. Gastrointestinal manifestations of SARS-CoV-2 infection and virus load in fecal samples from a Hong Kong cohort: systematic review and meta-analysis. Gastroenterology 2020; 159: 81-95

[10] Hayee B, The SCOTS project group, East J et al. Multicentre prospective study of COVID-19 transmission following outpatient GI endoscopy in the UK. Gut 2020: doi:10.1136/gutjnl-2020-322730

[11] Repici A, Aragona G, Cengia G et al. Low risk of COVID-19 transmission in Gl endoscopy. Gut 2020; 69: 1925-1927

[12] Alboraie M, Piscoya A, Tran QT et al. The global impact of COVID-19 on gastrointestinal endoscopy units: An international survey of endoscopists. Arab J Gastroenterol 2020; 21: 156-161

[13] Urakawa S, Hirashita T, Momose K et al. Intraluminal gas escapes from biopsy valve and endoscopic devices during endoscopy: caution advised during the COVID-19 era. Endosc Int Open 2021; 09: E443-E449

[14] Chen J-H, Yu Y, Yang Z et al. Intraluminal pressure patterns in the human colon assessed by high-resolution manometry. Sci Rep 2017; 7: 41436

[15] Hirota M, Miyazaki Y, Takahashi T et al. Dynamic article: steady pressure $\mathrm{CO} 2$ colonoscopy: its feasibility and underlying mechanism. Dis Colon Rectum 2014; 57: 1120-1128

[16] Bojórquez A, Larequi FJZ, Betés MT et al. Commercially available endoscopy facemasks to prevent aerosolizing spread of droplets during COVID-19 outbreak. Endosc Int Open 2020; 08: E815-E816

[17] Endo H, Koike T, Masamune A. Novel device for preventing diffusion of aerosol droplets from subjects undergoing esophagogastroduodenoscopy during COVID-19 pandemic. Dig Endosc 2020; 32: e140e141

[18] Zhiqin W, Muhammad Nawawi KN, Raja Ali RA. Application of an antiaerosol box for esophagogastroduodenoscopy during the COVID-19 pandemic: double up the protection. Endoscopy 2020; 52: 704-705 
[19] Kikuchi D, Suzuki Y, Nomura K et al. New safety measure for the endoscopic procedures during the COVID-19 pandemic: New STEP. VideoGIE 2020; 5: 634-636
[20] Leow VM, Mohamad IS, Subramaniam M. Use of aerosol protective barrier in a patient with impending cholangitis and unknown COVID19 status undergoing emergency ERCP during COVID-19 pandemic. BMJ Case Rep 2020; 13: e236918 